SAND76-0682

Unlimited Release

Printed April 1977

\title{
SIMULATION OF PERSONNEL CONTROL SYSTEMS \\ WITH THE INSIDER SAFEGUARDS EFFECTIVENESS MODEL (ISEM) ${ }^{\text {** }}$
}

Drayton D. Boozer

Systems Studies and Engineering Division 1754

Dennis Engi

Systems Analysis Division I, 5741

Sandia Laboratories

Albuquerque, New Mexico 87115

\begin{abstract}
Nuclear safeguards systems are being designed to prevent theft or sabotage of radioactive material by persons employed in nuclear facilities. As incidents of terrorism have increased, the need for more advanced safeguards systems has been recognized. Dynamic simulation models have been found useful in determining relative safeguards system effectiveness. A simulation model which treats certain aspects of the insider problem is the Insider Safeguards Effectiveness Model (ISEM). This report describes the model, discusses its role in analysis and design of safeguards systems, and explains the use of the model in conjunction with other models used for safeguards system design. Effectiveness results and sensitivities to safeguard system parameter variations are reported, and a comprehensive example of ISEM use for a hypothetical facility is given.
\end{abstract}

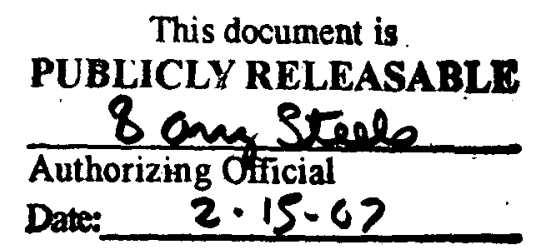

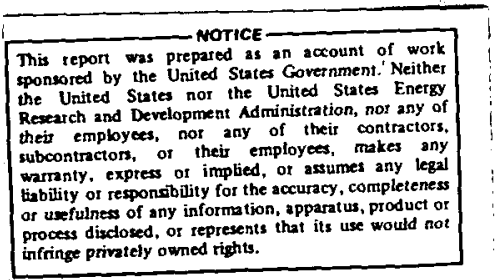

infringe privitely owned rights.

*This study is sponsored by ERDA Division of Safeguards and Security and NRC Division of Safeguards, Fuel Cycle, and Environmental Research. 


\section{DISCLAIMER}

This report was prepared as an account of work sponsored by an agency of the United States Government. Neither the United States Government nor any agency Thereof, nor any of their employees, makes any warranty, express or implied, or assumes any legal liability or responsibility for the accuracy, completeness, or usefulness of any information, apparatus, product, or process disclosed, or represents that its use would not infringe privately owned rights. Reference herein to any specific commercial product, process, or service by trade name, trademark, manufacturer, or otherwise does not necessarily constitute or imply its endorsement, recommendation, or favoring by the United States Government or any agency thereof. The views and opinions of authors expressed herein do not necessarily state or reflect those of the United States Government or any agency thereof. 


\section{DISCLAIMER}

Portions of this document may be illegible in electronic image products. Images are produced from the best available original document. 
I. Introduction and Summary

II. Description of ISEM

III. Utilization of ISEM in Facility Safeguards System Analysis and Synthesis

IV. ISEM Analysis of a Hypothetical Facility

V. Conclusions

\section{FIGURES}

\section{Figure}

1 ISEM Conceptual Facility Layout

2 ISEM Facility Characterization Facility Entities with Insider Paths

3 Ordering of the Four Insider Paths Investigated; Three Response Guards, Two Insiders (One Employee, One Guard)

4 ISEM Modeled Facility with Critical Path (A), Response Guards and Path Sensors

5 Safeguards System Performance as a Function of Number of Guards for Insider Path A; Two Insiders (One Employee, One Guard)

6 Identification of Critical Sensor Subsystems for Insider Path A; Three Response Guards, Two Insiders (One Employee, One Guard)

7 Relationship of Sensor Subsystems 22 and 23 to Insider Path A

8 Safeguards System Performance vs. Alarm Probability for Sensor 11 Located in Area 5; Two Response Guards, Two Insiders (One Guard, One Employee)

9 Safeguards System Performance (Conditional Probability of System Win) Tradeoff Between Adding Guards and Increasing Sensor Subsystem 11 Performance

10 Safeguards System Performance vs. Amount of Mixed Oxide Carried by the Insider; Three Response Guards, Two Insiders (one Employee, One Guard) 
SIMULATION OF PERSONNEL CONTROL SYSTEMS

WITH THE INSIDER SAFEGUARDS EFFECTIVENESS MODEL (ISEM)

I. Introduction and Summary

Nuclear safeguards systems are being designed to prevent persons employed at nuclear facilities from participating in either the theft of special nuclear material (SNM) or the sabotage of the facility in such a way that radioactive material is released into the environment beyond the facility boundaries. This design goal is complicated by the fact that some facility personnel must have access to SNM in order to perform their assigned tasks.

For the purpose of this report, an insider is defined as a facility employee whose goal is to perpetrate either theft or sabotage. There are numerous strategies an insider may employ to achieve his goal. One strategy is to use high energy explosives to sabotage the facility, thereby potentially releasing radioactive material. A second strategy is to divert small amounts of SNM from the process stream over a sufficiently long period of time to avoid detection by the accounting system and then use force to remove the accumulated SNM from the facility. In a third possible strategy the insider simply seizes the SNM, possibly from a storage area, and forces his exit from the facility.

In the past, material accounting systems (studied through Diversion Path.Analysis ${ }^{1}$ ) and security clearance investigations have been relied upon to counteract the insider threat. As incidents of terrorism ${ }^{2}$ have increased, so has the need for more advanced safeguards.systems to deal with the forcible entry threat. Concurrently, the insider problem has received renewed attention because of the growing number of people having authorized access to nuclear facilities, and the general awareness of the characteristic of SNM.

It has become clear that new approaches must be developed to study the insider safeguards problem and that there must be an increased level of physical protection afforded SNM. The goal in the design of physical protection.safeguards systems should be to balance the effectiveness of the design over some range of threat and expected consequences subject to a prespecified safeguards cost constraint. Sandia Laboratories has found both analytical and Monte Carlo simulation models useful in estimating relative safeguards effectiveness for alternative safeguards system design options. A simulation model which treats certain aspects of the insider problem is the Insider Safeguards Effectiveness Model (ISEM). * Although ISEM can be used to study the

\footnotetext{
ISEM was developed under the sponsorship of ERDA Division of Safeguards and Security.
} 
safeguards system at a nuclear facility generally, the purpose of this report is to describe ISEM and to demonstrate its use in modeling the personnel control system of a hypothetical facility. This paper has been written on the safeguards system analyst level; however, a glossary has been included to aid readers not familiar with safeguards terminology. Those readers interested in a more thorough discussion of ISEM should see Reference 3.

This report is organized as follows: A general description of ISEM is presented in Section $I$, and a discussion of ISEM!'s role in the analysis and design of safeguards systems is provided in Section III. Also contained in Section III is a discussion of the use of ISEM in conjunction with other methods which are currently being used in safeguards system design. A comprehensive example is given in Section IV to show typical ISEM effectiveness results and sensitivities to variations in. several safeguards system parameters. The appendix contains a discussion of the current status of ISEM and presents a number of projected extensions.

\section{Description of ISEM}

ISEM is a model used to evaluate facility safeguards system effectiveness for threats posed by insiders. A separate model has been developed to simulate forcible attacks by external threats on a nuclear facility. That model, the Forcible Entry Safeguards Effectiveness Model (FESEM), is described in Reference 4.

.The general safeguards problem posed by the insider threat requires consideration of material control, material accounting, and personnel control systems (Glossary, Page 25). ISEM was developed to treat specifically those insider attacks in which the time relationship among scenario events is important. The concept of attack detection leading to a safeguards system response is central to the model. The set of scenario events for one attack may include events from the material control, material accounting, and personnel control systems; however, there is no distinction made between these major safeguards subsystems within the model. An important class of insider scenarios treated by ISEM is one in which some response by security guards is required to prevent the successful completion of the insiders' attack. ISEM can model either theft or sabotage attacks which consist of both nonforcible and forcible adversary actions.

Among the effectiveness measures which can be obtained from ISEM are estimates of (1) the probability of at least one alarm along the adversary path, (2) the probability of at least one encounter between the adversary and response guards along the adversary path, and (3) the probability that the adversary is thwarted along the adversary path either by encounters with guards or by being caught in portals. In the remainder of this report, the third measure is considered to be the probability of system win. For all measures the results are conditioned on an attack by the adversary. 
Figure 1 illustrates the conceptual facility layout used in ISEM. The facility consists of three basic entities: Areas, Portals, and Barriers. Detection elements such as area, point, or line sensors can be located at these facility entities. Area sensors are used to detect living and inanimate objects within given areas while point sensors generate alarms at specific locations. Line sensors detect intrusions of a given line such as one extending along a perimeter fence.

Each sensor has a specified facility location, and associated with each sensor is a set of logic points and alarm points. Logic points are those locations where sensor information flow can be interrupted. Examples of logic points are sensor threshold control points (e.g., a potentiometer in a portal) and computer logic and memory points (e.g., a microprocessor used to control sensor alarms). The sensor communication lines which connect sensors, logic points, and alarms are assumed to be secure; but the logic points are susceptible to degradation by insiders. Alarm points are locations where a sensor alarm annunciates. For example, a buzzer in the security control area sounds in response to a door opening on a facility's exterior.

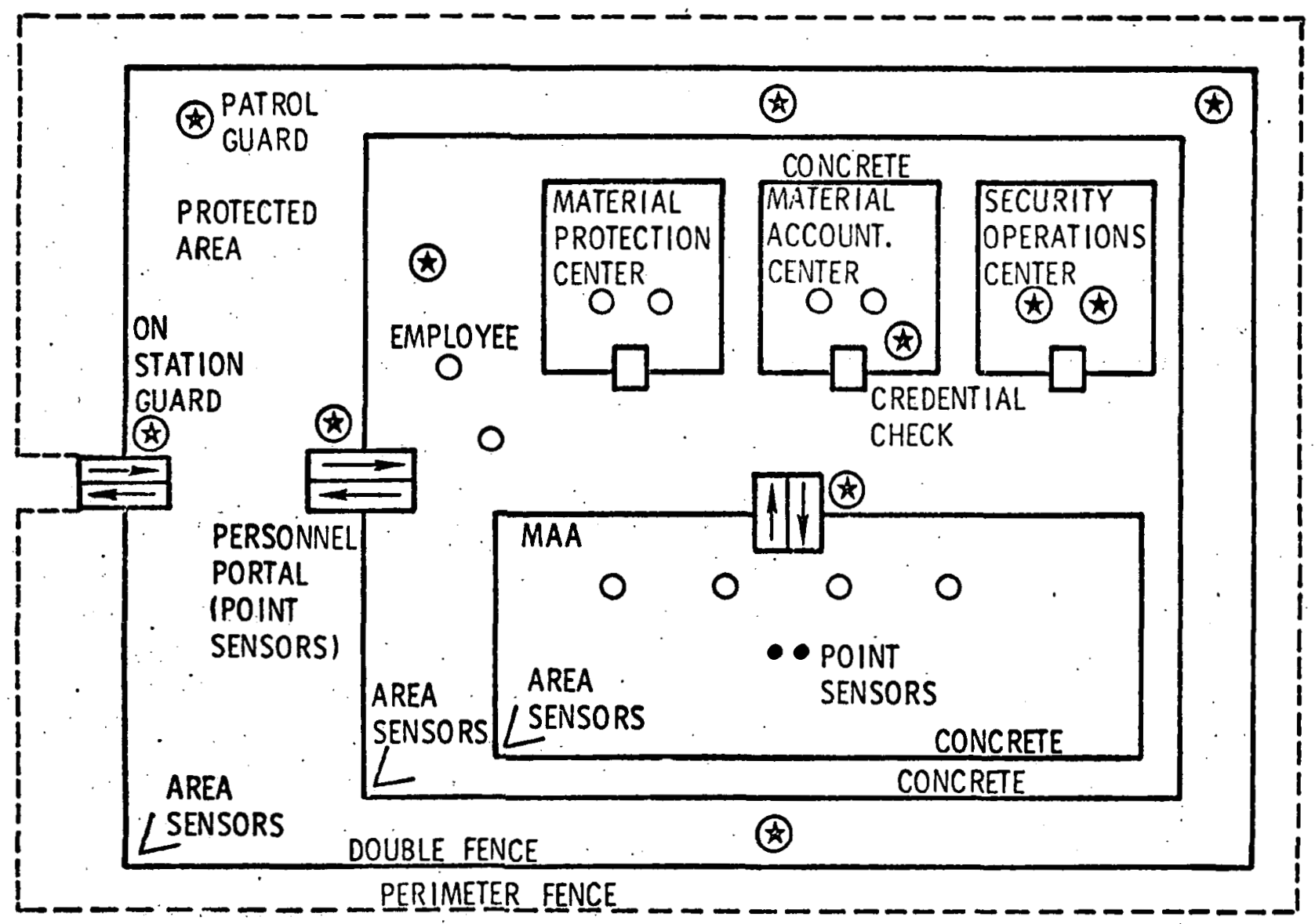

Figure 1. ISEM Conceptual Facility Layout 
Insider access areas are compared with both logic and alarm points to determine which sensors might be modified by the insider. The defeat of any logic point for a particular sensor insures defeat of all alarms for that sensor. The defeat of any alarm point for a particular sensor is considered to be independent of the defeat of all other alarm points. If an insider has appropriate access, probabilistic outcomes based on input point probability assignments are used to determine if the logic or alarm points are defeated. The probability of successful tampering is also affected by the personnel density and the existence of surveillance sensors in the area.

SNM sensors, both gamma and neutron, are modeled more precisely than other sensors in ISEM because (1) they are fundarnental in countering diversion and (2) their operation is well understood. Consideration is given to the amount, type, composition, enrichment, burn-up, shielding, and location of the SNM on the insider. SNM sensor characteristics and local environmental conditions are used to determine the background count rate which, in turn, determines the sensor threshold.

Metal and explosive sensors are modeled using functional relationships between the effective mass of material and the alarm probability. Sources of metal include weapons and shields for explosives and SNM. The effect of the shield on the operation of the SNM and explosive sensors is described by attenuation factors. Although metal sensor performance is being evaluated and some data are available, the sensor was not modeled in detail because of the large number of variables which significantly impact performance and the difficulty in specifying these variables.

One of the more useful features of ISEM is its flexibility. For example, for sensors whose performance is not well established, simple functional models can be used to generate alarm probabilities until more accurate, detailed models are evolved based on experimental and/or operational information. On a less detailed level, alarm probabilities may be specified directly. For example, personnel may be considered as sensors. Because ISEM is a simulation model, it can be extended to include safeguards system features which were not initially considered.

In general, the insider threat is subdivided into insider guards and other employees. It is assumed that the strategy of the insider(s) is to attack the sensor system elements covertly before the potentially forceful actions are taken during the interaction phase of the scenario. It is further assumed that only one insider carries the SNM, explosives, firearms, tools, and other materials. Therefore, only one insider (either guard or employee) can become involved in an engagement with the guard forces. The only difference in the effect on the scenario caused by an insider employee and an insider guard is that guards have access to both Areas and Portals, whereas employees have access only to Areas. Therefore, insider guards can defeat sensor system elements located in Portals; but insider employees cannot. Insider guards covertly attack the sensor system but at most one guard may interact overtly with the guard response force. For example, if the threat is an insider employee who carries the SNM and one guard, the guard cannot interfere with the response of the remainder of the guard force to alarms generated by the insider employee. 
It is evident from Figure 1 that a large number of possible insider paths exist. ISEM requires that an insider path be identified. Generally, only a subset of facility entities and sensors is involved in a particular insider path; however, ISEM is structured so that facility data can be stored initially and then used for any path chosen for analysis.

Upon activation, each sensor in the facility has a prespecified guard response that is initiated following a specified delay. This response entails moving the security guards to strategic locations within the facility. Since the specific guard responses must be determined in advance, a good overall safeguards system should evolve in consideration of the spectrum of feasible adversary scenarios and paths.

Once an adversary is encountered and a confrontation is in progress, the guard(s) engaged in the confrontation may sound a "call for help." Following the call for help, some or all of the remaining response guards are directed to the confrontation with the purpose of subduing the adversary. Some of the guards can be designated as nonresponse guards and held in reserve even if there is a call for help. This hold-back technique is a viable safeguards tactic for counteracting adversary diversionary tactics as well as providing an adversary containment mechanism.

The actual confrontation between guards and adversaries is modeled as a discrete-state/ continuous-time stochastic process. ${ }^{5}$ The states are the number of combatants actively involved in the confrontation. Transition times between states are assumed to be continuous random variables which are a function of the force size, weapons, and competence of the opposing forces. Distributions of the transition times, along with a count of the number of guard arrivals at the confrontation site, completely determine the engagement process. For example, in an encounter involving two guards and an adversary, three initial transitions from this initial state are possible. One guard can be disabled; the adversary can be disabled; or another guard can arrive at the encounter site. The states of the model change until either all guards or the adversary are disabled.

III. Utilization of ISEM in Facility Safeguards System Analysis and Synthesis

The method used to structure the safeguard system evaluation problem is to assess safeguards system effectiveness in coping with a specified set of adversary strategies which are designed to achieve the adversary's goal of either theft of SNM or sabotage of the facility so that SNIM is dispersed. The range of strategies selected determines the scope of the analysis. For a given strategy, a set of scenarios is established to achieve the adversary's goal. A subset of the scenario events are those which may result in forceful actions being taken by the adversary, if necessary, after detection occurs. The route used by the adversary during this phase of the scenario is called the "path." 
ISEM simulates both the interaction of the insider with the facility safeguards system along the path and the "a priori,". covert defeat of sensor systems by any designated group of insiders. Therefore, ISEM simulates scenarios but emphasizes the interaction of the insider with the safeguards system elements along a path. Which some subjective probability assignments must be made by the users, ISEM gives relative estimates of safeguards system effectiveness along a path which provides a method for comparing safeguards system alternatives. Given the set of alternatives and their costs, the most cost effective system can be chosen.

To estimate a facility's safeguards system effectiveness, many adversary strategies, each having numerous scenarios and paths, must be considered. Since the number of paths for the strategy set treated by ISEM is virtually limitless, some technique is necessary to choose a subset of paths to be studied in detail by ISEM. This is currently accomplished by graph theoretic techniques, event/fault tree techniques, or by the analyst. 6

Because some scenarios consist solely of events whose time dependence is of secondary importance, the dynamic capability of ISEM is not required in their evaluation. For those scenarios, alternative techniques should be considered. For example, if the adversary's strategy is to avoid detection, then detection may be equated with safeguards system effectiveness.

It is emphasized that while ISEM simulates one scenario at a time, many scenarios may be run with only the path specific data being changed between simulations.

IV. ISEM Analysis of a Hypothetical Facility

- A. Description.

Consider the facility shown in Figure 2. The threat consists of one insider guard and one insider employee. The insiders' strategy is to first defeat sensor system elements, obtain a significant amount of $\mathrm{PuO}_{2}$ in Area 5 , then have the insider employee exit the facility through the personnel portals. It is assumed that the insider employee in Area 5 has a handgun. The smuggling of the handgun into Area 5 can be studied using ISEM if guard response to its detection is important, otherwise a success probability for this part of the scenario can be calculated directly. The latter approach is taken in this example. In the following discussion, the terms effectiveness, safeguards effectiveness, and path effectiveness are used synonymously with the conditional probability of safeguards system win for the specified path. The probability results are estimates of the true probability given the model assumptions. Extrapolation of these results to the actual facility requires a tacit acceptance of the model assumptions. 


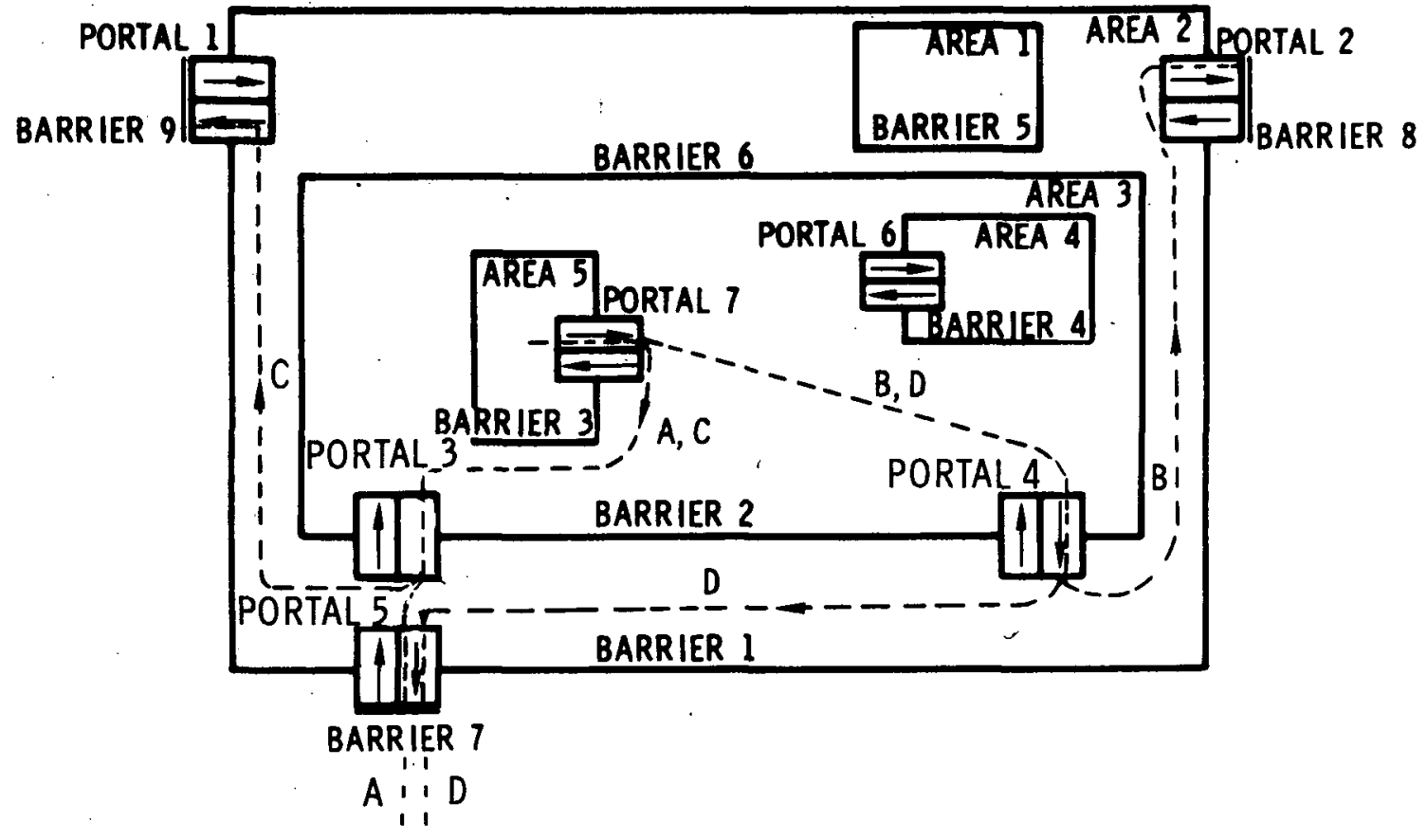

Figure 2. ISEM Facility Characterization-Facility Entities with Insider Paths

B. Critical Path Determination.

After the safeguards system elements have been described, the four insider employee paths shown in Figure 2 are analyzed to determine the "critical" path. Here, criticality is measured in terms of the probability of a safeguards system win. The results for these four paths are shown in Figure 3. Assuming the facility layout is to scale and the insider has the same average speed on all paths, the "shortest time" path is also the critical path (see Figure 2). This, in general, would not be true since there could easily be imbalances in the sensor coverage, guard deployment, and insiders' access authorizations. While the results displayed in Figure 3 are statistically significant given the ISEM set of assumptions, the actual effectiveness might be quite different since subjectivity is involved both in ISEM input data and in the structure of ISEM.

C. Effectiveness Sensitivity to Number of Response Guards.

Having determined the critical path (A) from the path constraint set for the specified insider strategy, the number of guards is varied to determine the system effectiveness sensitivity for path (A). The critical insider path, response guard locations, and sensor locations along the critical path are shown in Figure 4. For the situation depicted in Figure 4, there are three response guards, two in Area 1 and one in Area 2. The responses of the guards to the alarms are prespecified for each alarm in the system. For example, suppose that the SNM sensor located in Area 3 just outside Portal 7 is activated as the adversary passes with stolen SNM. The prespecified guard responses to this alarm entail sending one guard from Area 1 to Portal 1, one guard from 
Area 1 to Portal 2, and the guard in Area 2 to Portal 5. The goal of this strategy is to contain the adversary within the facility by blocking each of the exit portals. Generally, when the number of guards is changed, the deployment and responses of guards for a specific alarm will change.

Figure 5 shows the results of these runs. Notice that there is a low probability of a system win when the number of response guards drops below three. The reason for this is that there are three exterior portals which must be "covered" to insure containment of the insider. One cannot assume knowledge of the insider path when the guard responses are formulated; therefore, all exterior portals should be covered. An asymptote of approximately 0.75 is approached as the number of guards is increased because the probability of no alarm activating a response remains the same regardless of the number of guards. The results indicate that the safeguards system effectiveness with respect to this critical path and set of guard tactics is insensitive to increases in number of guards beyond three.

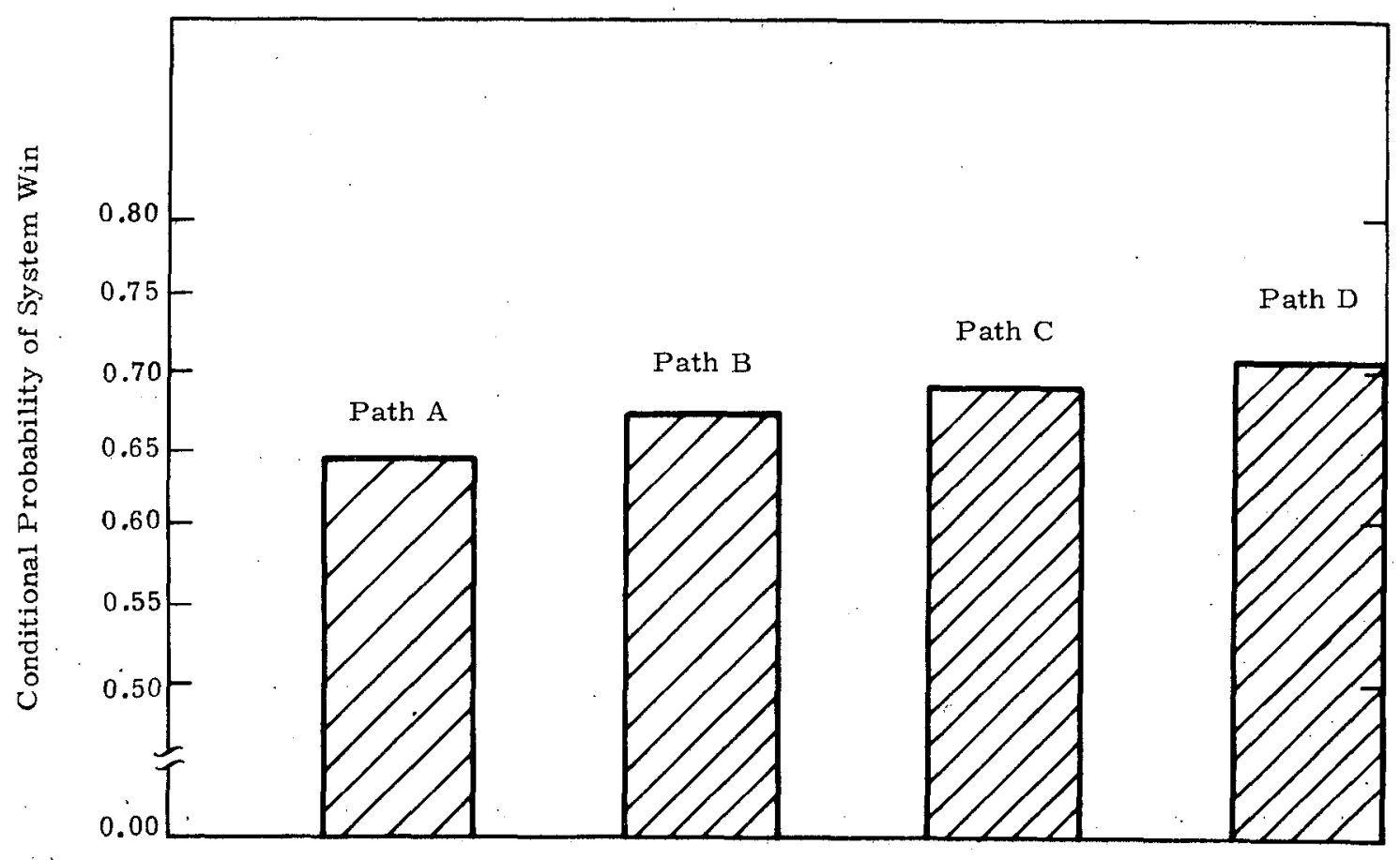

Figure 3. Ordering of the Four Insider Paths Investigated; Three Response Guards, Two Insiders (One Employee, One Guard) 


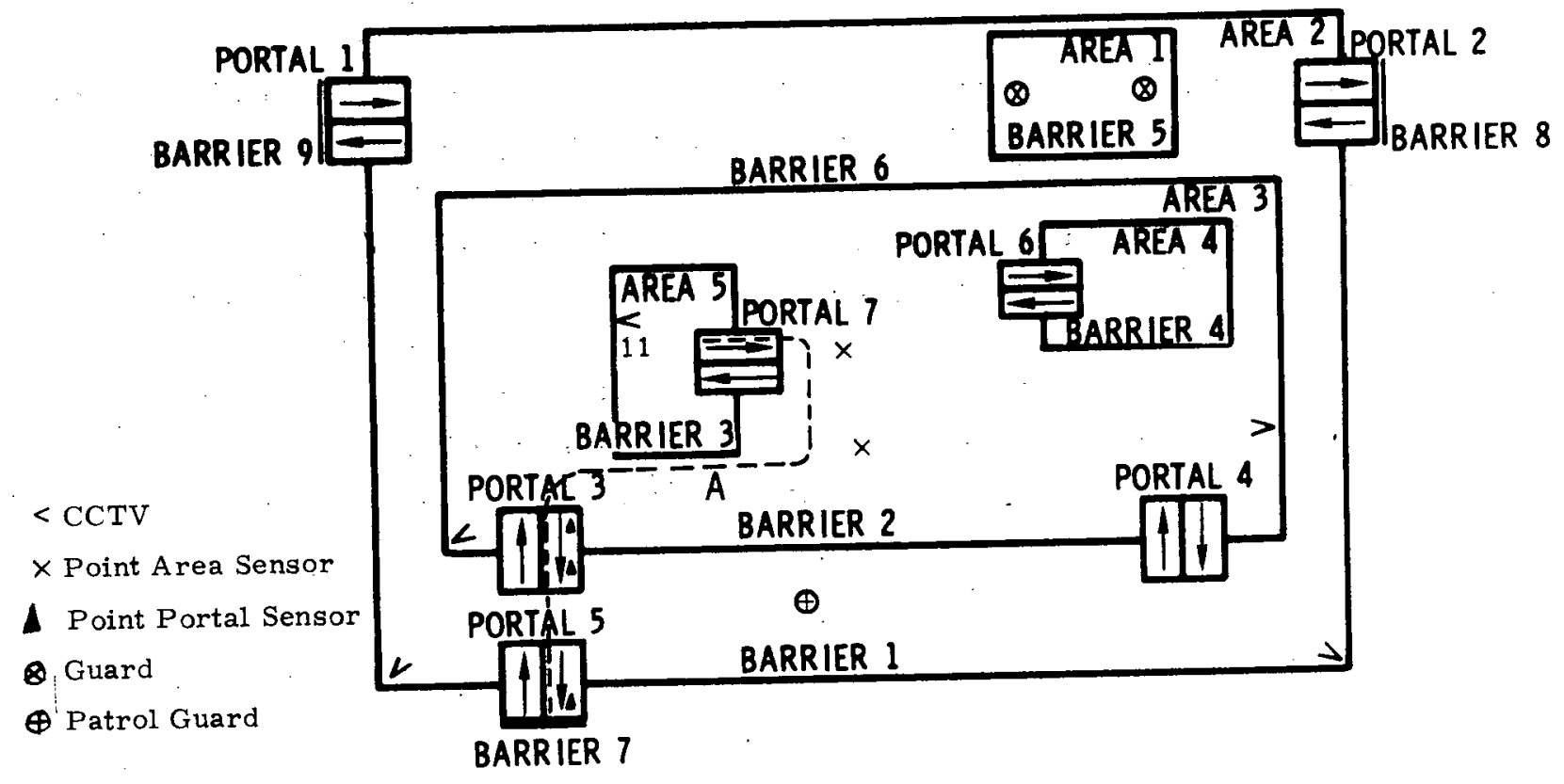

Figure 4. ISEM Modeled Facility with Critical Path (A), Response Guards and Path Sensors

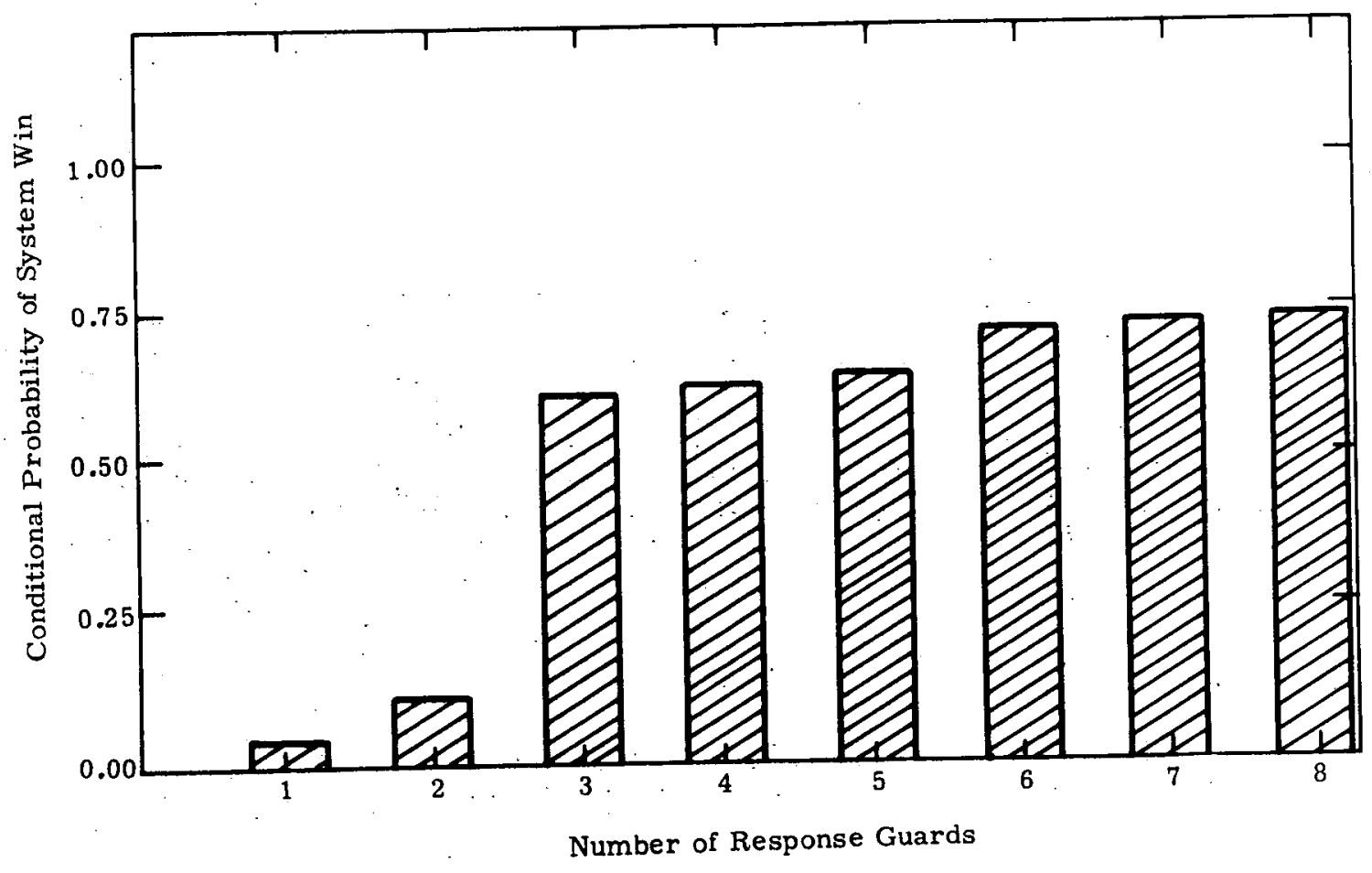

Figure 5. Safeguards System Performance as a Function of Number of Guards for Insider Path $A_{\text {; }}$ Two Insiders (One Employee, One Guard) 
D. Effectiveness Sensitivity to Sensor Systems.

The safeguards effectiveness sensitivity to the sensor systems was also examined. By studying ISEM output data, Sensors 22 and 23 which are the gamma and neutron sensors located in Portal 3 are identified as vital sensors. In order to quantify this sensitivity, the two sensors are removed individually and as a pair. Since the insider carries a large amount of unshielded $\mathrm{PuO}_{2}$, the probability of sensor activation is essentially 1 if there is no insider degradation. The results of these runs are shown in Figure 6, and the configuration for the sensor system elements is shown in Figure 7. As could be predicted from Figure 7, Sensor System 22 is more critical than 23 because the insiders cannot degrade the Sensor 22 alarm located in Area 1 and the two sensor subsystems are otherwise identical. When both sensors are removed, path effectiveness drops below 0.20 (see Fig. 6).

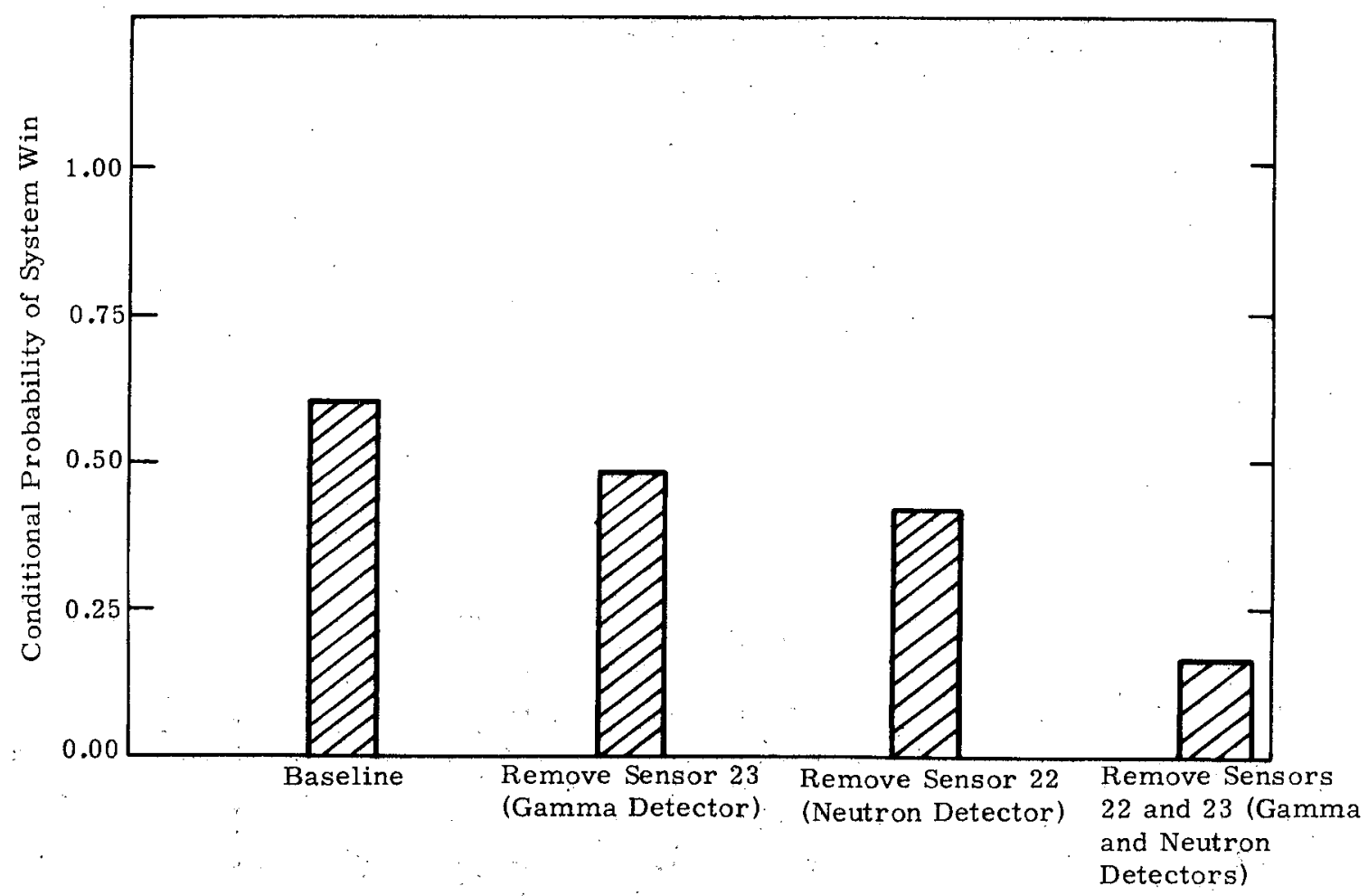

Figure 6. Identification of Critical Sensor Subsystems for Insider Path A; Three Response Guards; Two Insiders (One Employee, One Guard) 


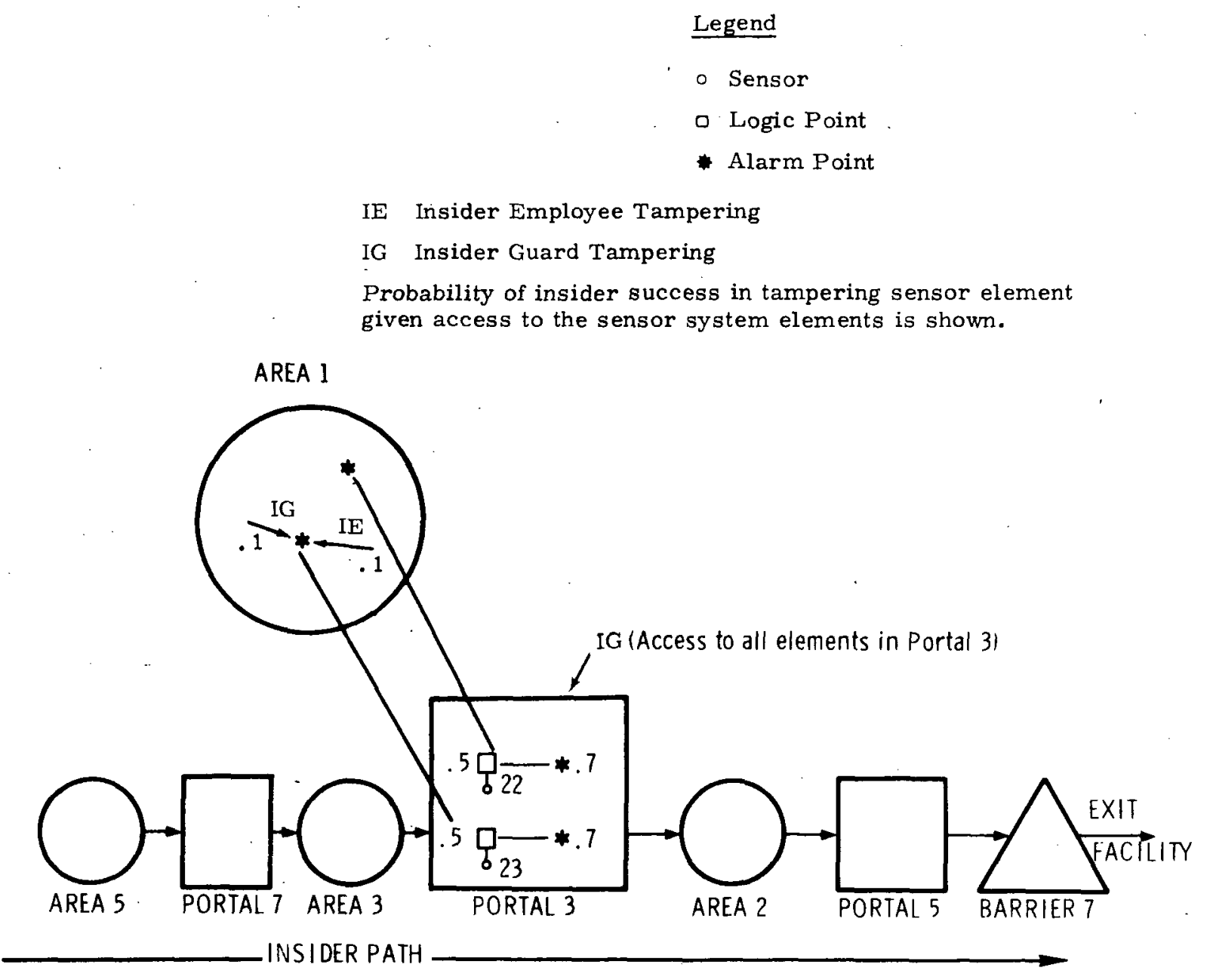

Figure 7. Relationship of Sensor Subsystems 22 and 23 to Insider Path A

E. Effectiveness Tradeoff Between Sensor Systems and Response Guards.

Since the guards alone do not provide significant increases in the path effectiveness, one might consider upgrading Sensor 11 located in Area 5 (see Figure 4). Since this sensor generates alarms early in the path, it should yield increased path effectiveness when its probability of alarm is increased. The alarm probability was varied from 0.1 to 0.9 in steps of 0.2 with the results shown in Figure 8. It is somewhat surprising that there is little change in effectiveness as the alarm probability is increased. The results are explained as follows. When Sensor 11 alarms, one guard is sent to assess the cause. For the specified time relationships, it is probable that an engagement will ensue. The guard may be defeated by the insider in this situation; however, when sensors which are placed later along the path generate an alarm, it is probable that the assessment guard will arrive while the insider is in a portal--and this leads, with certainty, to a guard win. It is tacitly assumed that the insider can be held in the portal until an adequate response force can arrive. This case illustrates that an early detection may not be more desirable than a 
later one unless guard tactics are modified. One may think of the portal delays as time gates during which guard arrivals are more effective than guard arrivals during other path segments.

Suppose the probability of defeating the alarm for Sensor 11 decreases as the alarm sensitivity and reliability is increased (alarm probability increases). That is, attention is given to tamperproofing the alarm at the same time the alarm probability is increased. The variation in path effectiveness for the number of guards and the performance of Sensor 11 is shown in Figure 9 .

The results for one and two guards appear to be counter-intuitive. The explanation is found in the guard responses. For the early alarm on Sensor 11, the response guard is sent to Portal 7 from Area 2; but many times the guard arrives after the insider exits Portal 7, therefore eliminating the opportunity to stop the insider unless a call for help is initiated when the guard arrives at Portal 7. On the other hand, when either Sensor 22 or 23 alarms, the patrol guard is sent to Portal 3 from Area 2 and the likelihood is high that the guard will arrive while the insider is still in the portal. Guard arrivals while the insider is in a Portal are more effective than guard arrivals when the insider is in an Area. It is not productive to summon a guard to a location where he is less effective.

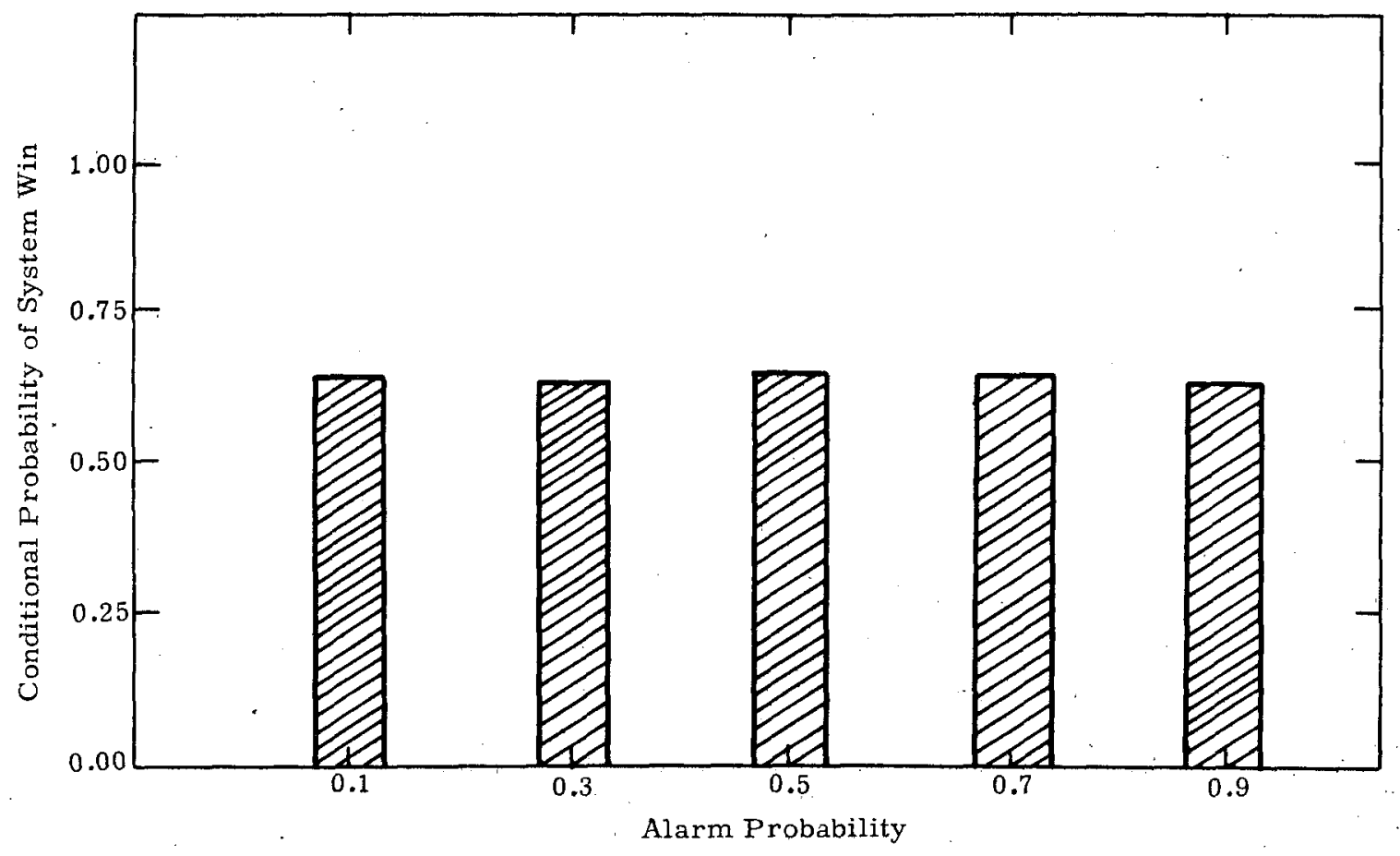

Figure 8. Safeguards System Performance vs. Alarm Probability for Sensor 11 Located in Area 5; Two Response Guards, Two Insiders (One Guard, One Employee) 


\begin{tabular}{|c|c|c|c|c|}
\hline \multirow[b]{2}{*}{$\begin{array}{l}\text { Number of } \\
\text { Response Guards }\end{array}$} & 0.1 & 0.5 & 0.9 & $\begin{array}{l}\text { Probability of Untampered } \\
\text { Alarm } \\
\end{array}$ \\
\hline & 0.3 & $\cdot 0.2$ & 0.1 & $\begin{array}{l}\text { Probability Insider Defeats } \\
\text { Alarm }\end{array}$ \\
\hline 1 & 0.05 & 0.02 & 0.01 & \\
\hline 2 & 0.11 & 0.09 & 0.03 & \\
\hline 3 & 0.61 & 0.62 & 0.58 & \\
\hline 4 & 0.63 & 0.67 & 0.64 & \\
\hline 5 & 0.64 & 0.71 & 0.74 & \\
\hline 6 & 0.71 & 0.78 & 0.90 & \\
\hline 7 & 0.71 & 0.74 & 0.92 & \\
\hline 8 & 0.71 & 0.82 & 0.92 & \\
\hline
\end{tabular}

Figure 9. Safeguards System Performance (Conditional Probability of System Win) Tradeoff Between Adding Guards and Increasing Sensor Subsystem 11 Performance

For three and four response guards, the situation is as explained in the discussion of Figure 8. When more than four guards are available, the increased sensor performance results in significant increases in path effectiveness because if engagements are initiated the probability is high that the guards will win. The simulation repeatability for these results is in the range of $0.03-0.05$.

This example illustrates that ISEM can be used to determine facility guard deployment and tactics to insure safeguards system effectiveness over a range of adversary strategies.

F. Effectiveness Sensitivity to Amount of SNM.

Since ISEM models the SNM portal sensors, a set of three runs was made to determine the impact on the overall path effectiveness of the amount of mixed oxide carried by the insider. The ISEM user can model the presence of shielding material, select the effective area, integration time, threshold setting of the SNM sensors. It is assumed that surveillance sensor alarm probabilities are unchanged over the set of runs. Therefore, results are indicative of material carried in the same manner for the cases simulated. The results are shown in Figure 10. Two observations are important: (1) the SNM sensors practically saturate, i. e., have probability of alarm of essentially 1 above 10 grams of $\mathrm{MO}_{2}$; and (2) the sensors still contribute to path effectiveness when only 0.1 gram of $\mathrm{MO}_{2}$ is carried. 


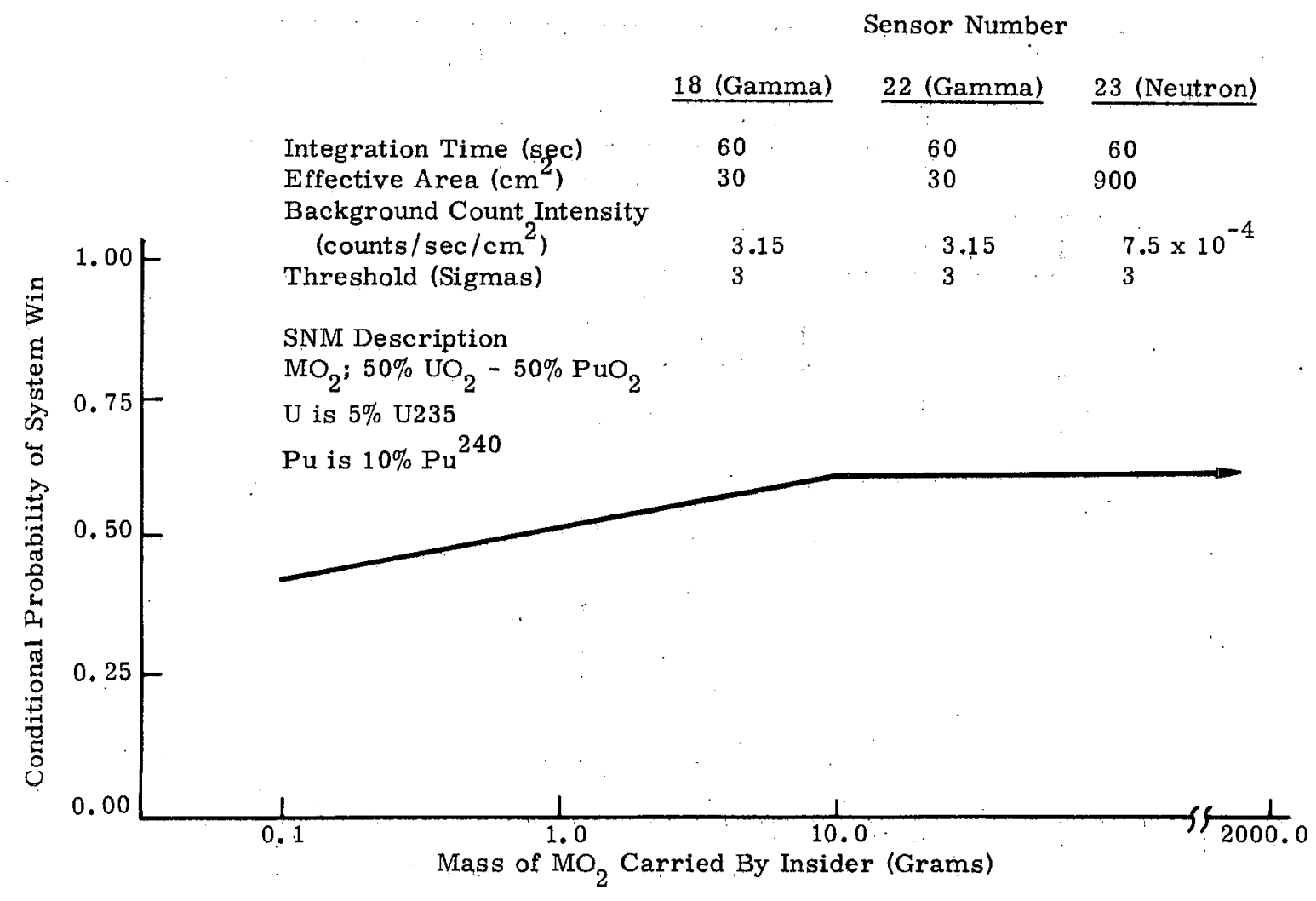

Figure 10. Safeguards System Performance'vs, Amount of Mixed Oxide Carried by the Insider; Three Response Guards, Two Insiders (One Employee, One Guard)

G. Effect of Entry Path on Results.

It has been assumed throughout this analysis that the insider in Area 5 has a handgun. In some facilities, it might be difficult to introduce a handgun into vital areas without detection. For these cases, system wins resulting from handgun detection must be considered.

Let $\mathrm{H}$ be the event that the handgun is not detected during the insider entry sequence, $\mathrm{S}$ be the event of system win on either entry or exit paths, and $S / H$ the conditional event of system win given that the handgun is not detected on entry to Area 5. Then the probability of a system win is

$$
\begin{aligned}
& P(S)=P[(S \cap H) U(S \cap \bar{H})] \\
& P(S)=P(S \cap H)+P(S \cap \bar{H}) \\
& P(S)=P(H) P(S / H)+P(\bar{H}) P(S / \bar{H})
\end{aligned}
$$

Now assume that a detection on entry is a system win, which implies, $P(S / \bar{H})=1.00$. Therefore,

$$
P(S)=P(H) P(S / H)+P(\bar{H})
$$


Suppose two metal detectors are in all possible paths into Area 5. Suppose further that the probability is 1 that the untampered metal detector will alarm for a handgun, but the insider alarm defeat probability for the metal detector is,0.40. Then the probability that no detection occurs on entry assuming both insiders have access to the alarm, is given by

$$
P(\bar{H}) \text { a } 1-(1-0.4)^{2}=0.64
$$

Therefore, the probability of a safeguards system win is

$$
P(S)=0.36 \mathrm{P}(\mathrm{S} / \mathrm{H})+0.64
$$

where $\mathrm{P}(\mathrm{S} / \mathrm{H})$ is determined by ISEM. For example, from Figure 3, Path $\mathrm{A}$, the conditional probability of system win, $\mathrm{P}(\mathrm{S} / \mathrm{H})$ is 0.60 . Therefore $\mathrm{P}(\mathrm{S})$ equals 0.86 . Note that the system probability of win for both entry and exit paths, $P(S)$, is bounded by $0.64[P(S / H)=0.0]$ and $1.0[\mathrm{P}(\mathrm{S} / \mathrm{H})=1.0]$. For this example, if the insider is never stopped during exit, $\mathrm{P}(\mathrm{S} / \mathrm{H})=0.0$ and $P(S)=0.64$. Therefore, the effectiveness results are improved considerably when metal detectors are assumed to exist at all entry locations. If access paths to Area 5 other than through portals are available to the insider, $P(\bar{H})$ should be replaced with the lowest probability of system win among the set of handgun smuggling paths. It should be noted that this calculation can be made without resorting to an ISEM simulation since detection is considered to be a defeat for the insider. If insider interaction with the safeguards systems following detection is required, ISEM should be used.

An interesting point that one should consider when using ISEM is the extent to which additional information available from each simulation is used in the design and analysis of the facility safeguards system. For example, one can determine the percentage of cases for which the insider won and no guard was encountered, the percentage of cases for which no alarm activated, the percentage of cases for which guards were deployed, but never arrived, etc. It might be a viable safeguards tactic to attempt to catch the adversary in a portal in order to reduce the number of engagements. It could be argued that two safeguards systems which produce equivalent effectiveness results but lead to different guard casualty rates are not equally desirable systems.

In this section, a fairly detailed example of ISEM's use in the design of personnel control systems has been presented. Other approaches and sets of assumptions are possible. Reference 3 describes ISEM in detail and explains the operations required to use it. 


\section{Conclusions}

ISEM uses simulation techniques to analyze the effectiveness of a nuclear facility's safeguards system in coping with a group of insiders who use certain strategies to achieve theft of SNM or the sabotage of the facility. The specific application of ISEM to determine the effectiveness of a hypothetical facility's personnel control system to one particular adversary scenario has been treated in this report. ISEM's primary contribution to the evaluation of personnel control systems, as well as more general safeguards systems, is its ability to simulate the response of the safeguards system to alarms generated by sources such as sensors, personnel, or procedures. ISEM also addresses the tampering of sensor system elements by insiders. By studying the characteristics of the safeguards system response (usually guards) to a range of insider scenarios, effective operational procedures can be developed. These considerations are essential, for example, in coping with insider diversionary attacks. 


\section{APPENDIX I}

ISEM Status and Future Extensions

Development of ISEM was initiated in February 1976. ISEM's primary application to date has been in the conceptual design of a mixed-oxide fuel fabrication facility. ${ }^{7}$ An ISEM Sandia users' guide ${ }^{6}$ has been written and will be published in the near future. ISEM is currently undergoing testing by Sandia organizations and is being executed in batch mode on Sandia's CDC 6600 computers. A simulation consisting of 500 runs of a typical path requires 30 seconds of central processor time. ISEM is a discrete event simulation written in GASP IV. It requires $105000_{8}$ 60-bit memory locations. Current plans are to install ISEM on the Sandia CDC 6600 NOS time sharing system. Integration of ISEM with a graphical input/output capability is envisioned. 
1. Diversion Path Analysis Handbook, Vol. 1, Methodology NBS Document SIRM-77, July 1976 (FINAL DRAFT).

2. Brian M. Jenkins, Terrorism and the Nuclear Safeguards Issue, RAND Paper P-5611, The RAND Corporation, Santa Monica, CA, March 1976.

3. D. D. Boozer and D. Engi, Insider Safeguards Effectiveness Model (ISEM); Sandia User's Guide, SAND77-0043, Sandia Laboratories, Albuquerque, NM,

4. Leon D. Chapman, Fixed-Site Physical Protection System Modeling, SAND 75-6061, Sandia Laboratories, Albuquerque, NM, 1975.

5. Dennis Engi, A Small-Scale Engagement Model with Arrivals: Analytical Solutions, SAND77-0054, Sandia Laboratories, Albuquerque, NM, April 1977.

6. D. D. Boozer, et. al., Safeguards System Effectiveness Modeling, SAND 76-0428, Sandia Laboratories, Albuquerque, NM, September 1976.

7. A. E. Winblad, et. al., A Concept and Preliminary Definition of an Engineered Safeguards System for a Mixed-Oxide Fuel Fabrication Facility (U), SAND 76-0528, Sandia Laboratories, Albuquerque, NM, September 1976 (Conf.). 
Gilossary

NUCLEAR FACILITY - facilities which process, store, or use special nuclear material (SNM)

SABOTAGE - the willful release of SNM from a nuclear facility by either using explosives to release SNM directly or destroying facility components so that SNM release will ultimately result and cause societal risk

THEFT - the unauthorized removal of SNM beyond the facility boundary

SAFEGUARDS SYSTEM - the set of components, personnel, and procedures used at a facility to protect SNM and/or critical facility components

MATERIALS MEASUREMENT AND ACCOUNTING SYSTEM - a subsystem of the facility safeguards system used to determine the quantity and location of SNM at a facility

MATERIAL CONTROL SYSTEM - a subsystem of the facility safeguards system used to prevent unathorized access to SNM at a facility

PERSONNEL CONTROL SYSTEM - a subsystem of the facility safeguards system used to prevent unauthorized personnel access to certain locations at a facility

PHYSICAL PROTECTION SYSTEM - a subsystem of the facility safeguards system used to prevent the theft of SNM or the sabotage of the facility

INSIDER - a malefactor having authorized access to a facility including authorized access to material

STRATEGY - the generic method used by an adversary to achieve the goal of theft or sabotage of SNM or the sabotage of the facility

SCENARIO - the specific set of activities used by an adversary to achieve his goal

PATH - the specific route used by an adversary performing scenario activities during which an alarm can result in overt actions by the adversary

TACTICS - the response of facility guards to alarms generated by the facility safeguards system 


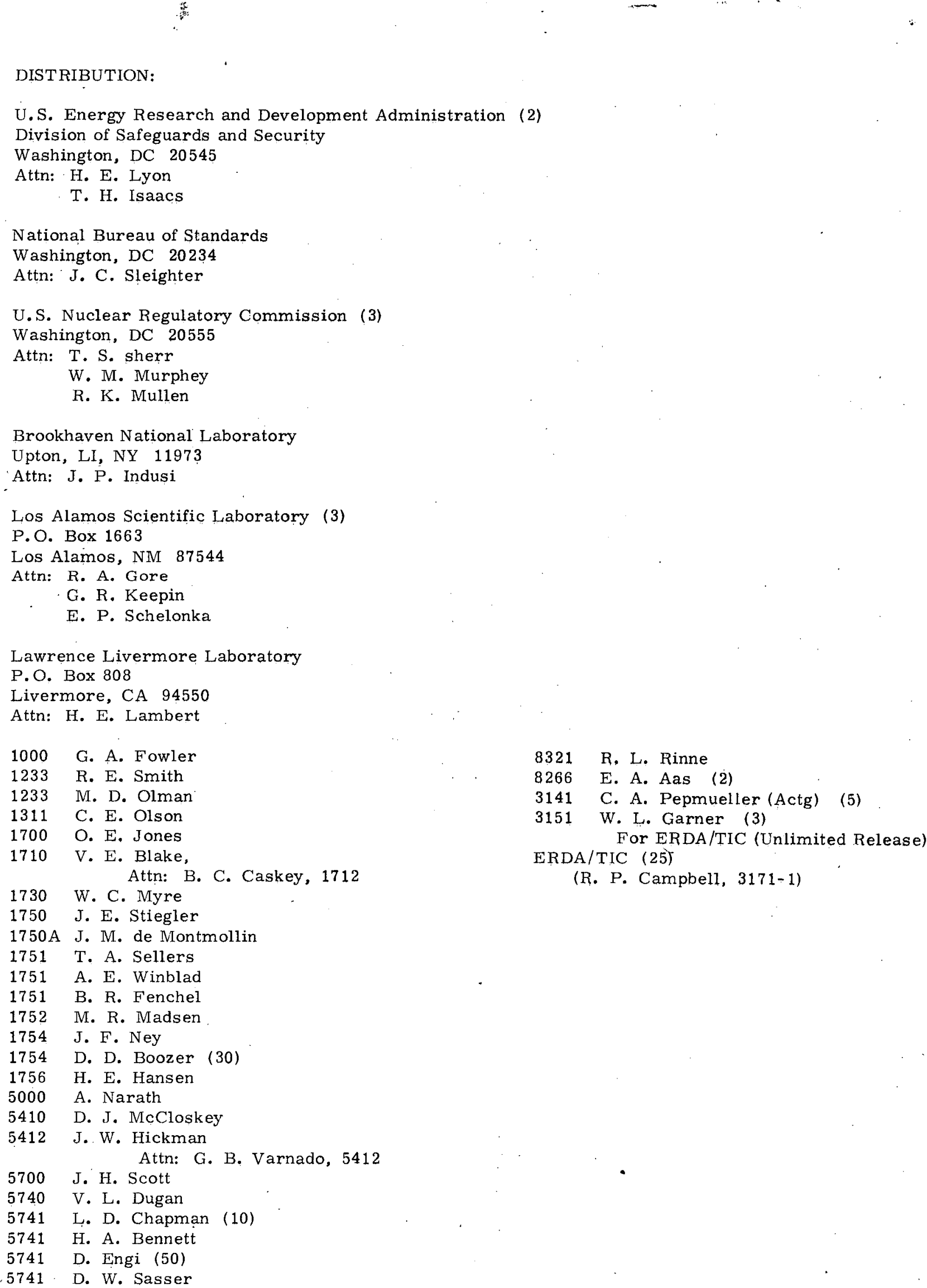

DISTRIBUTION:

U.S. Energy Research and Development Administration (2) Division of Safeguards and Security

Washington, DC 20545

Attn: H. E. Lyon

T. H. Isaacs

National Bureau of Standards

Washington, DC 20234

Atț: J. C. Sleighter

U.S. Nuclear Regulatory Commission (3)

Washington, DC 20555

Attn: T. S. sherr

W. M. Murphey

R. K. Mullen

Brookhaven National Laboratory

Upton, LI, NY 11973

Attn: J. P. Indusi

Los Alamos Scientific Laboratory

(3)

P.O. Box 1663

Los Alamos, NM 87544

Attn: R. A. Gore

G. R. Keepin

E. P. Schelonka

Lawrence Livermore Laboratory

P.O. Box 808

Livermore, CA 94550

Attn: H. E. Lambert

\begin{tabular}{ll}
1000 & G. A. Fowler \\
1233 & R. E. Smith \\
1233 & M. D. Olman \\
1311 & C. E. Olson \\
1700 & O. E. Jones \\
1710 & V. E. Blake, \\
& \multicolumn{1}{l}{ Attn: B. C. Caskey, 1712 } \\
1730 & W. C. Myre \\
1750 & J. E. Stiegler \\
1750 A & J. M. de Montmollin \\
1751 & T. A. Sellers \\
1751 & A. E. Winblad \\
1751 & B. R. Fenchel \\
1752 & M. R. Madsen \\
1754 & J. F. Ney \\
1754 & D. D. Boozer (30) \\
1756 & H. E. Hansen \\
5000 & A. Narath \\
5410 & D. J. McCloskey \\
5412 & J. W. Hickman \\
& \\
5700 & J. H. Scott G. B. Varnado, 5412 \\
5740 & V. L. Dugan \\
5741 & L. D. Chapman (10) \\
5741 & H. A. Bennett \\
5741 & D. Engi (50) \\
5741 & D. W. Sasser
\end{tabular}

8321 R. L. Rinne

8266 E. A. Aas (2)

3141 C. A. Pepmueller (Actg) (5)

3151 W. L. Garner (3)

For ERDA/TIC (Unlimited Release) ERDA/TIC (25)

(R. P. Campbell, 3171-1) 